\title{
REPRODUKSI ASEKSUAL PADA Holothuria atra (ECHINODERMATA) DI TELUK MEDANA, LOMBOK BARAT
}

\author{
Sigit Anggoro Putro Dwiono ${ }^{1)}$, Pradina Purwati'i), Varian Fahmi'1), dan Lisa F. Indriana1) \\ 1) Peneliti pada Loka Pengembangan Bio Industri Laut-Pusat Penelitian Oseanografi- \\ Lembaga Ilmu Pengetahuan Indonesia, Pemenang-Lombok Barat \\ 2) Peneliti pada Pusat Penelitian Oseanografi-Lembaga Ilmu Pengetahuan Indonesia, Ancol-Jakarta \\ Teregristrasi I tanggal: 16 Oktober 2008; Diterima setelah perbaikan tanggal: 19 Nopember 2008; \\ Disetujui terbit tanggal: 20 Nopember 2008
}

\begin{abstract}
Beberapa jenis timun laut secara alamiah memiliki kemampuan untuk berkembang biak secara aseksual melalui pembelahan (fission). Penelitian ini merupakan studi pertama tentang reproduksi aseksual alamiah timun laut di perairan Indonesia. Di Teluk Medana, Lombok Barat, Nusa Tenggara Barat fenomena reproduksi aseksual ini ditunjukkan oleh populasi Holothuria atra. Untuk mengetahui intensitas, musim, dan peran reproduksi ini dalam memelihara populasi, dilakukan monitoring bulanan mulai bulan Pebruari 2007 sampai Pebruari 2008. Hasil tersebut menunjukkan bahwa reproduksi aseksual pada populasi Holothuria atra ini terjadi sepanjang tahun. Intensitas pembelahan (fission intensity) maksimum mencapai $32,69 \%$, yang berarti bahwa $1 / 3$ dari populasi melakukan pembelahan. Variasi laju pembelahan (fission rate) berkisar antara 1,79 dan 23,68\%. Pada bulan Mei 2007, komponen individu hasil pembelahan hampir mencapai separuh $(47,4 \%)$ dari jumlah individu keseluruhan. Ketiga indikator ini cukup untuk menyimpulkan bahwa reproduksi aseksual pada Holothuria atra di Medana berperan dalam memelihara populasi di habitat tersebut. Topik ini sangat penting diteliti mengingat peran reproduksi aseksual ini dalam mempertahankan keberadaan di alam.
\end{abstract}

KATAKUNCI: Holothuria atra, reproduksi aseksual, pembelahan, Medana, Lombok Barat

ABSTRACT: Asexual reproduction on Holothuria atra (Echnodermata) at Medana Bay, West Lombok. By: Sigit Anggoro Putro Dwiono, Pradina Purwati, Varian Fahmi, and Lisa F. Indriana

\begin{abstract}
Several species of sea cucumbers are able to reproduce asexually through fission. This study is the first report on fission of holothurian populations in Indonesian waters. At Medana Bay, West Lombok, fission was demonstrated by Holothuria atra population. To determine the intensity, season, and the role of fission on the population maintenance, monitoring was conducted on monthly basis, from February 2007 until February 2008. This study revealed that fission occurred throughout the year. Maximum fission intensity was 32,69\%, implying that one third of the population underwent fission. Fission rate which was illustrated by the frequency of fission products during 13 month of observations, varied between 1.79 and 23.68\%. In May 2007, fission products composed nearly half (47.4\%) of the population. These three indicators may be sufficient to conclude that asexual reproduction in Holothuria atra population at Medana Bay might contribute significantly in maintaining its population size. This research topic seems important to be carried out considering the role of asexual reproduction in maintaining its natural population.
\end{abstract}

\section{KEYWORDS: Holothuria atra, asexual reproduction, fission, Medana, West Lombok}

\section{PENDAHULUAN}

Secara alamiah, beberapa jenis timun laut memiliki kemampuan untuk memperbanyak diri melalui reproduksi seksual maupun aseksual dengan cara membelah diri (fission). Emson \& Wilkie (1980) mendefinisikan fission pada reproduksi aseksual timun laut sebagai pembelahan tubuh menjadi bagian anterior (A) yang membawa kompleks mulut dan posterior $(\mathrm{P})$ yang membawa kompleks anus.

Purwati (2001b), menyimpulkan bahwa sampai dengan saat ini baru 10 jenis timun laut yang diketahui memiliki kemampuan membelah diri yaitu Actinopyga difficilis (Deichmann, 1922), Cucumaria lactea, C. planci (Smiley et al., 1988), Holothuria atra (Conand, 1996; Harriott, 1982), Holothuria edulis (Uthicke, 1997), Holothuria leucospilota (Conand et al., 1997; Purwati, 2001b; Townsley \& Townsley, 1973), Holothuria parvula (Emson \& Mladenov, 1987), Holothuria surinamensis (Crozier, 1917), Stichopus chloronatus (Conand et al., 1998; Uthicke, 1997) dan S. horrens (Harriott, 1980; Kohtsuka et al., 2005). Jenis-jenis ini kemudian dikelompokkan sebagai holothuria yang secara alami mampu membelah diri (fissiparous holothurians). Lima jenis antara lain banyak ditemukan di Indonesia yaitu Holothuria atra, 
Holothuria edulis, Holothuria leucospilota, S. Chloronatus, dan S. horrens.

Holothuria atra merupakan jenis yang populasi sudah beberapa kali dikatakan melakukan reproduksi aseksual, termasuk populasi di Taiwan, Pulau Reunion, dan paparan karang Heron (Chao et al., 1993; Conand, 1996; Harriott, 1982). Di Indonesia, fenomena pembelahan diri alamiah ini belum pernah dikatakan, walaupun indikasi ditemukan pada beberapa populasi termasuk Holothuria atra di perairan Medana Lombok Barat (Purwati, 2006) dan di Aceh (Yusron, komunikasi langsung). Hal yang menarik dalam aspek reproduksi tipe ini bahwa tidak semua populasi spesies fissiparous melakukan reproduksi aseksual (Purwati, 2001a; 2001b).

Konsekuensi reproduksi aseksual pada populasi fissiparous antara lain ukuran individu yang lebih kecil dari populasi dari jenis sama yang hanya melakukan reproduksi seksual, dan memiliki densitas tinggi. Contoh yang paling jelas Holothuria atra di Nanwan dan Wanlitung, Taiwan, yang jarak antara ke-2 habitat hanya sekitar 20 mil (Chao et al., 1993; 1994). Di Indonesia, keberadaan Holothuria atra sudah cukup banyak dikatakan termasuk di Aceh, Kepulauan Seribu dan Lampung, serta Tajung Pai Padaido, Papua (Aziz \& Hakim, 2001; Hartati et al., 2002; Yusron, 2003, 2006). Populasi yang dikatakan berukuran relatif kecil dan belum ada informasi tambahan yang berhubungan dengan peristiwa reproduksi aseksual.

Penelitian ini ditujukan untuk mempelajari fenomena reproduksi aseksual pada populasi timun laut Holothuria atra di perairan Medana, Kecamatan Tanjung, Lombok Barat. Dari penelitan ini diharapkan diperoleh informasi yang lengkap mengenai peran reproduksi aseksual dalam mempertahankan keberadaan di alam dan gambaran mengenai kemungkinan pemanfaatan sebagai alternatif perbanyakan jumlah individu untuk tujuan pemulihan populasi timun laut yang telah menipis di berbagai daerah.

\section{BAHAN DAN METODE}

Penelitian reproduksi aseksual dilakukan selama 13 bulan mulai bulan Pebruari 2007 sampai dengan Pebruari 2008 di perairan pesisir Medana, Kecamatan Tanjung, Kabupaten Lombok Barat.

Lahan pengamatan sebuah lahan (mikrohabitat) seluas kurang lebih $2.078 \mathrm{~m}^{2}$ yang hanya dihuni oleh timun laut jenis Holothuria atra (Gambar 1). Lahan ini disebut sebagai lokasi Medana ke-4 (M4) yang merupakan daerah yang selalu terendam air, bersubstrat keras dengan lapisan pasir yang tipis, banyak memiliki patahan karang dan sedikit ditumbuhi lamun dengan densitas $<30 \%$ (Purwati, 2006; Purwati et al., 2008). Pada saat air surut ketinggian air 60 sampai dengan $100 \mathrm{~cm}$.

Karena lahan relatif kecil, maka pengumpulan Holothuria atra dilakukan dengan menyapu seluruh lahan ini dengan cara berenang menggunakan snorkel (snorkeling) oleh 4 sampai dengan 5 orang. Semua Holothuria atra yang ditemukan dikumpulkan dan diidentifikasi kondisi berdasarkan pada hasil pengamatan pembelahan di laboratorium yang pernah dibuat (Purwati \& Dwiono, 2007), sebagai berikut:

1. Individu utuh adalah individu normal, di mana tentakel yang mengelilingi mulut di bagian anterior dan lubang anus pada ujung posterior tampak jelas, masing-masing dengan ukuran yang proporsional.

2. Individu anterior adalah individu dengan tentakel dan mulut jelas; lubang anus di bagian posterior tidak ada, atau membentuk tonjolan dalam proses regenerasi.

3. Individu posterior adalah individu dengan anus jelas; tentakel dan kompleks mulut di bagian anterior tidak ada, atau membentuk tonjolan dalam proses regenerasi.

Setelah identifikasi dan penghitungan masingmasing kelompok individu selesai dilakukan, semua timun laut dikembalikan ke tempat semula.

Dalam penelitian ini, laju pembelahan (fission rate) dihitung berdasarkan pada frekuensi individu hasil pembelahan di dalam populasi riil, menerapkan rumus Conand et al. (1997), yaitu:

$$
(F \%)=((A+P) \times 100 \%) / 2 \times n
$$

di mana:

$\mathrm{F}=$ laju pembelahan

$A=$ jumlah individu anterior

$\mathrm{P}=$ jumlah individu posterior

$\mathrm{n}=$ jumlah total individu yang tertangkap

Dalam pembelahan, jumlah individu yang dihasilkan 2 kali jumlah individu awal (2n). Individu anterior dan posterior memiliki kemampuan bertahan yang setara seperti hasil percobaan stimulasi pembelahan yang dilakukan di laboratorium (Purwati \& Dwiono, 2005; Dwiono et al., 2008), maka ideal, jumlah individu anterior dan posterior yang tertangkap sama banyak. Namun, dalam pengamatan ternyata individu anterior dan posterior tidak pernah ditemukan dalam jumlah yang sama banyak (karena berbagai faktor eksternal). Dengan asumsi bahwa jumlah hasil 
pembelahan (anterior atau posterior) yang lebih banyak sebagai hasil pembelahan riil, maka diajukan sebuah indeks lain yaitu Intensitas pembelahan (intensity of fission) dengan rumus sebagai berikut: di mana:

$\begin{aligned} A^{\prime} \text { atau } P^{\prime}= & \text { A atau } P \text { dengan jumlah terbanyak } \\ & \text { pada pengamatan bulan tertentu } \\ \mathrm{U} & =\text { jumlah individu utuh }\end{aligned}$ $\operatorname{IF}(\%)=\left(\left[A^{\prime}\right.\right.$ atau $\left.\left.P^{\prime}\right] \times 100 \%\right) /\left(U_{+}\left[A^{\prime}\right.\right.$ atau $\left.\left.P^{\prime}\right]\right) \ldots . .(2$

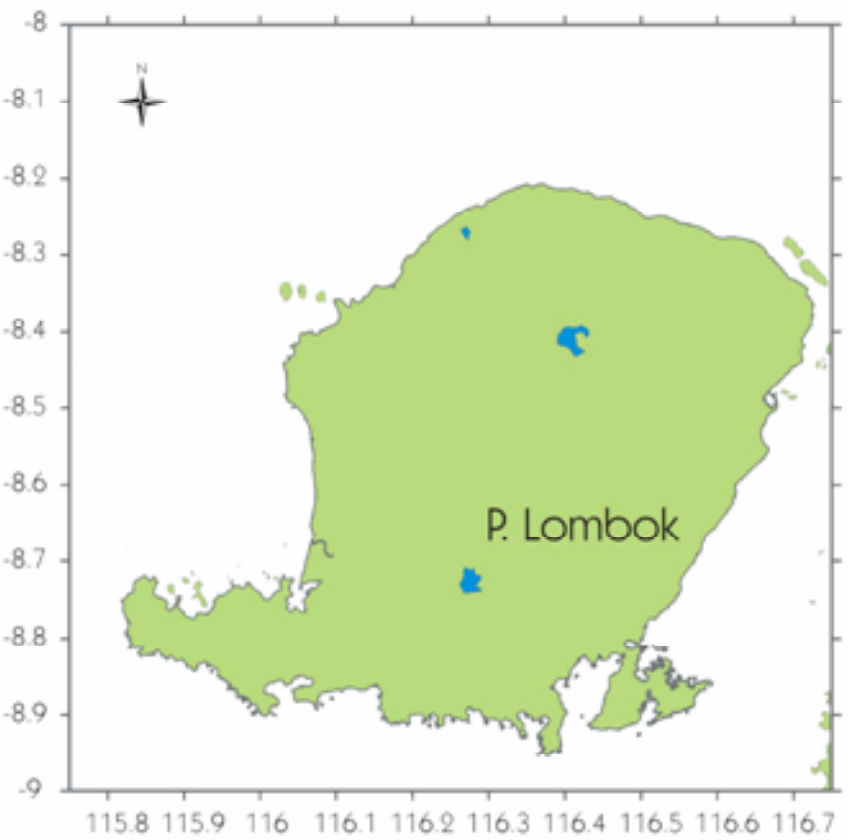

Gambar 1. Lokasi pengamatan (tanda bintang) reproduksi aseksual Holothuria atra di perairan Medana, Lombok Barat, Nusa Tenggara Barat.

Figure 1. Observation site (asteriks) of asexual reproduction of Holothuria atra at Medana waters, Lombok, Nusa Tenggara Barat.

\section{HASIL DAN BAHASAN}

Data hasil pengamatan reproduksi aseksual di perairan Medana disajikan dalam Tabel 1. Terlihat bahwa jumlah individu yang tertangkap setiap bulan bervariasi, yaitu berkisar antara 60 individu (bulan Pebruari 2008) sampai dengan 192 individu (bulan Juni 2007). Individu hasil pembelahan (A dan P) ditemukan sepanjang tahun, dengan persentase yang berbeda.
Jumlah $A$ dan $P$ tidak pernah sama sepanjang tahun, dan kecenderungan dominansi dalam periode 1 tahun pengamatan tidak tampak. Jumlah A lebih banyak dibandingkan $P$ ditemukan di 5 bulan pengamatan, yaitu bulan April, Mei, Juli, Nopember 2007, dan Pebruari 2008, sementara di 7 bulan yang lain, A lebih banyak dibandingkan P (Gambar 2). Dalam grafik juga tampak bahwa pada bulan Mei 2007, jumlah individu hasil pembelahan hampir mencapai separuh $(47,4 \%)$ dari jumlah individu dalam populasi Holothuria atra.

Tabel 1. Jumlah individu, laju pembelahan (fission rate), dan intensitas pembelahan (intensity of fission) populasi Holothuria atra di perairan Medana, Lombok Barat, Nusa Tenggara Barat

Table 1. Number of individuals, fission rate, and fission intensity in Holothuria atra population at Medana waters, Lombok Barat, Nusa Tenggara Barat

\begin{tabular}{lccccccc}
\hline \multirow{2}{*}{$\begin{array}{c}\text { Kriteria/ } \\
\text { Criteria }\end{array}$} & \multicolumn{2}{c}{ Kelompok individu/Group of individual } & \multirow{2}{*}{ ind. total } & F (\%) & IF (\%) \\
\cline { 2 - 4 } & $\sum$ ind. A & $\sum$ ind. P & $\sum$ ind.utuh & & 192 & 23,68 & 32,69 \\
Maksimum & 34 & 39 & 126 & 42 & 60 & 1,79 & 2,41 \\
Minimum & 1 & 2 & 17,54 & 94,08 & 125,08 & 11,67 & 17,0 \\
Rata-rata & 13,46 & 13,58 & 23,58 & 35.05 & 6,30 & 9,71 \\
Simpangan baku & 9,45 & & &
\end{tabular}


Intensitas Pembelahan (intensity of fission) berfluktuasi selama 13 bulan pengamatan, dan puncak tersebut terjadi pada bulan Mei 2007, di mana hampir sepertiqa (32.69\%) dari iumlah individu dalam populasi membelah diri. Kecenderungan (ternd) ini serupa dengan kecenderungan laju pembelahan (fission rate) (Gambar 3).

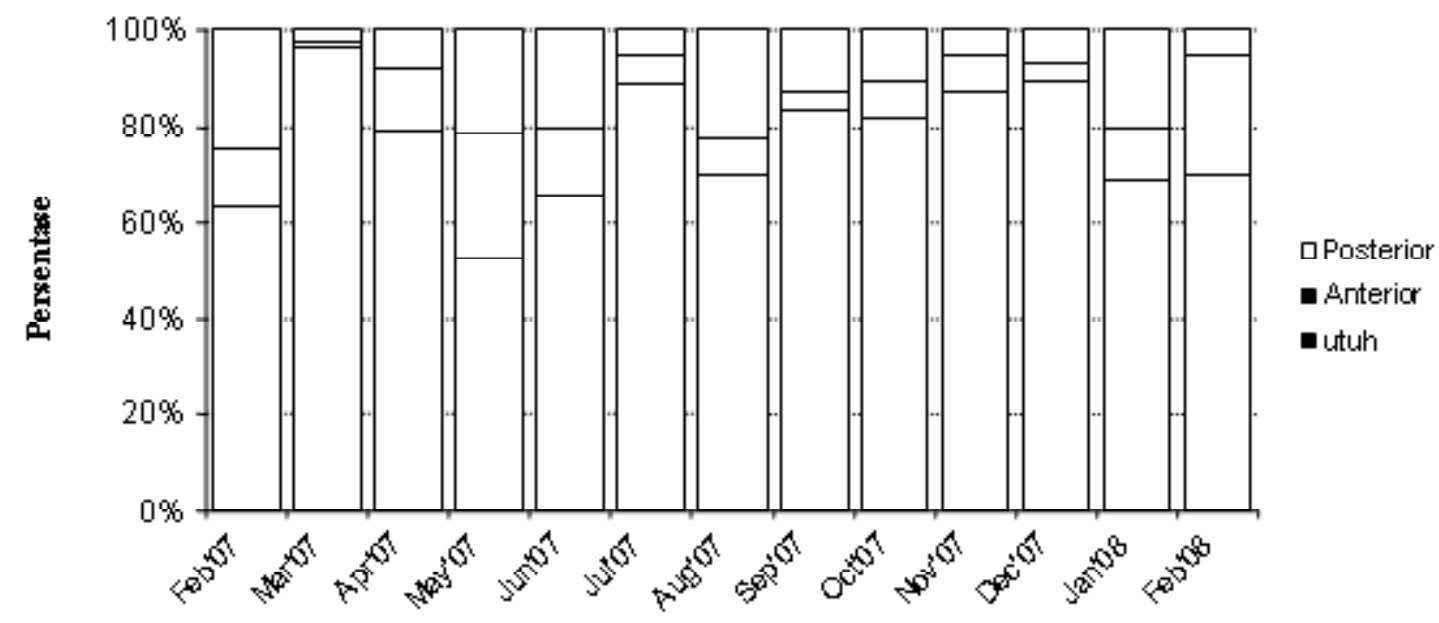

Waktu Pengamatan (bulan)

Gambar 2. Persentase individu A, P, dan utuh pada populasi Holothuria atra di perairan Medana, Lombok Barat, Nusa Tenggara Barat.

Figure 2. Percentage of $A, P$, and normal individuals in Holothuria atra population at Medana waters, Lombok Barat, Nusa Tenggara Barat.

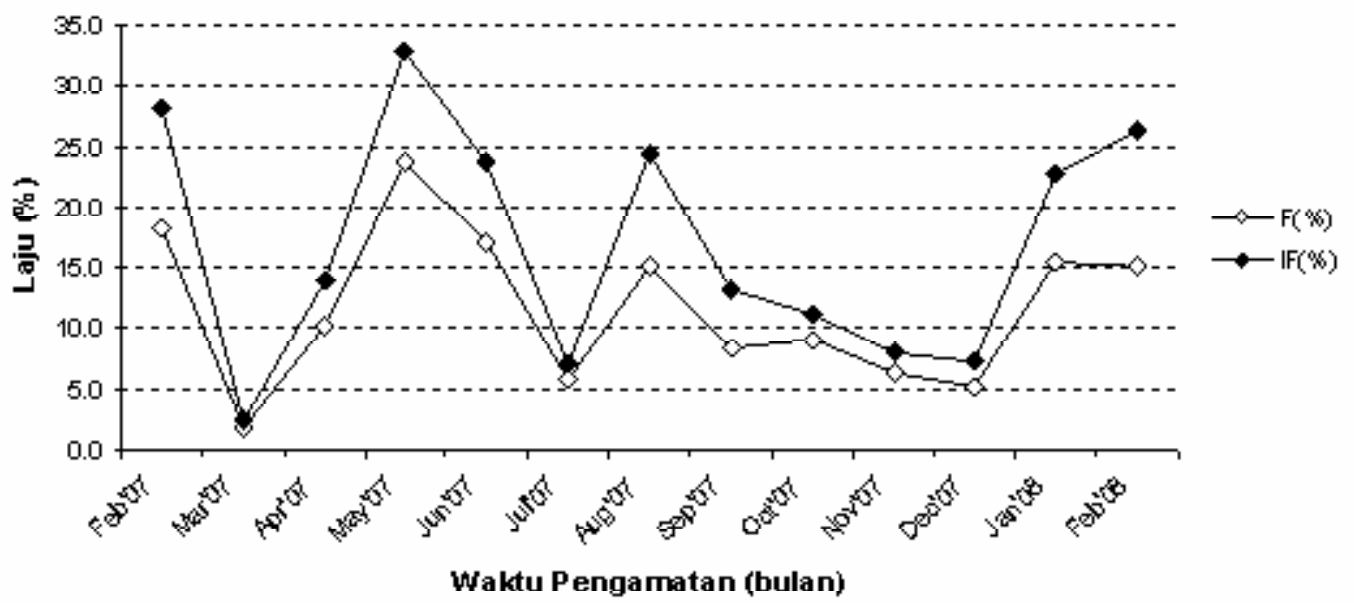

Gambar 3. Perubahan laju pembelahan (fission rate) dan intensitas pembelahan (intensity of fission) dalam populasi Holothuria atra selama pengamatan di perairan Medana, Lombok Barat.

Figure 3. Change of fission rate (fission rate) and intensity (intensity of fission) in Holothuria atra population during observation period at Medana waters, Lombok Barat.

\section{BAHASAN}

Selain di perairan Medana, Lombok Barat, reproduksi aseksual pada Holothuria atra di perairan Nusa Tenggara Barat pernah diamati (pengamatan pribadi) di perairan Kuta (bagian selatan Pulau Lombok) dan perairan Pulau Panjang (Sumbawa bagian barat). Pengamatan bulanan reproduksi aseksual alami yang dilakukan selama 13 bulan di perairan Medana menunjukkan bahwa jumlah yang tertangkap setiap bulan tidak tetap walaupun pencarian intensif telah dilakukan. Hasil penghitungan dengan metode yang sama pada bulan Juli 2006, individu yang ditemukan berjumlah 94 (Purwati, 2006). Dinamika semacam ini sangat umum terjadi karena berbagai faktor eksternal seperti kematian yang belum tergantikan, tersapu ombak, dan keberadaan juvenil yang terlalu kecil untuk diamati. 
Sebagaimana hal dengan reproduksi seksual, reproduksi aseksual dapat bersifat musiman atau sepanjang tahun. Reproduksi aseksual (pembelahan) populasi Holothuria atra di perairan Medana berlangsung sepanjang tahun. Pola ini sama dengan Holothuria leucospilota di perairan tropis Darwin, Australia utara (Purwati, 2004). Contoh reproduksi aseksual yang terjadi musiman pada populasi $S$. chloronotus di perairan Great Barrier Reefdan Reunion (Conand et al., 1998; Franklin, 1980; Uthicke, 1997). Terbuka kemungkinan fenomena pada jenis ini juga terjadi di perairan Indonesia.

Penelitian reproduksi aseksual terdahulu seperti Conand et al. (1997) pada umumnya dilaksanakan sesaat, sehingga tidak memungkinkan dilakukan estimasi peran aktivitas ini bagi kelangsungan keberadaan populasi. Purwati (2004) melakukan pengamatan yang cukup panjang di East Point dan Nightcliff di perairan utara Australia dan menemukan Holothuria leucospilota melakukan reproduksi aseksual sepanjang tahun. Dari nilai laju pembelahan (fission rate) dan komposisi ukuran individu dalam populasi disimpulkan bahwa reproduksi aseksual memiliki peran yang penting dalam mempertahankan jumlah optimum individu sesuai dengan daya dukung habitat.

Pada Holothuria atra di Medana, nilai fission rate tertinggi terjadi pada bulan Mei 2007 (23,68\%), dan produk pembelahan membangun $47,4 \%$ dari populasi. Dapat dikatakan bahwa reproduksi aseksual pada Holothuria atra memiliki peranan penting dalam mempertahankan populasi di Medana. Nilai ini lebih besar dibandingkan dengan laju pembelahan Holothuria atra di perairan Reunion yang mencapai 20\% (Conand, 1996). Variasi antar populasi dalam hal laju pembelahan terlihat juga pada Holothuria leucospilota di perairan utara Australia yang menunjukkan laju pembelahan $28 \%$ di East Point dan $8 \%$ di Nightcliff(Purwati, 2004), sedangkan di perairan Trou d'eau (Reunion) hanya 5,2\% (Conand et al., 1997).

Penelitian tahun 2006 terhadap populasi Holothuria atra, yang menimbang individu utuh yang dipilih secara acak memberi data berat tiris (tanpa air bebas) $123,5 \pm 35,3 \mathrm{~g}$ (rata-rata \pm simpangan baku) dengan jumlah 94 ind $2.000 \mathrm{~m}^{-2}$ atau 0,047 ind $\mathrm{m}^{-2}$ (Purwati, 2006). Ukuran ini cukup menggambarkan perbedaan dengan populasi Holothuria atra yang tidak melakukan reproduksi aseksual di Nanwan, Taiwan yang bobot maksimal mencapai $1.400 \mathrm{~g}$ dengan densitas 0,0024 ind $\mathrm{m}^{-2}$. Pada kasus Holothuria leucospilota, populasi yang tidak melakukan reproduksi aseksual di Pulau Heron memiliki bobot tubuh sampai dengan $1.200 \mathrm{~g}$ dengan densitas maksimum 0,25 m² (Franklin, 1980). Sementara itu, populasi yang melakukan pembelahan hanya mencapai $350 \mathrm{~g}$ di perairan Australia Utara dengan densitas 0,29 ind $\mathrm{m}^{-2}$ (Purwati, 2004).

Jumlah $\mathrm{A}$ dan $\mathrm{P}$ tidak pernah ditemukan dalam jumlah yang sama di habitat Teluk Medana. Selain itu, tidak ada kecenderungan (trend) khusus yang berhubungan dengan ratio jumlah A dan P. Keadaan ini mungkin menunjukkan bahwa ke- 2 bagian tubuh (anterior dan posterior) hasil pembelahan memiliki tingkat kelangsungan hidup yang sama. Beberapa percobaan stimulasi pembelahan yang dilakukan terhadap Holothuria atra mendukung kesimpulan ini, yang mana ke-2 belahan $A$ dan $P$ menunjukkan tingkat lolos hidup (survival rate) yang sama (Dwiono et al., 2008; Purwati \& Dwiono, 2005).

Hasil pemantauan pembelahan di Medana ini berbeda dengan beberapa hasil penelitian sebelum seperti pada Holothuria lecospilota di perairan Reunion (Conand et al., 1997), dan di perairan utara Darwin (Purwati, 2004), Holothuria atra di perairan Nanwan, Taiwan (Chao et al., 1993), dan S. chloronatus di Great Barrier Reef (Conand et al., 1997) di mana mortalitas bagian anterior lebih besar dibandingkan bagian posterior. Sementara itu, Emson \& Mladenov (1987) menemukan bahwa bagian tubuh anterior dan posterior Holothuria parvula memiliki tingkat kelangsungan hidup yang sama. Khusus pada Holothuria leucospilota, (Purwati, 2001b) menghubungkan dengan tingkah laku individu-indvidu. Secara alami, bagian posterior Holothuria leucospilota berpegang lebih kuat daripada bagian anterior, sehingga saat terjadi pembelahan, bagian anterior lebih mudah tersapu ombak.

Dalam penelitian ini, selain laju pembelahan (fission rate) juga digunakan formula lain untuk menggambarkan aktivitas reproduksi aseksual yaitu nilai intensitas pembelahan (intensity of fission). Ke2 parameter (fission rate dan intensity of fission) ini berubah dengan kecenderungan yang serupa. Dibandingkan dengan laju pembelahan (fission rate), intensitas pembelahan (intensity of fission) mungkin menggambarkan aktivitas reproduksi aseksual suatu populasi dengan lebih akurat. Nilai intensity of fission pada bulan Mei 2007 (32,69\%). Hal ini, berarti bahwa hampir sepertiga populasi Holothuria atra yang hidup di lokasi pengamatan membelah diri.

Berbagai faktor dapat mendorong terjadi reproduksi aseksual, namun faktor ini bersifat lokal dan spesifik seperti gagal reproduksi seksual, euthrofikasi, kelaparan, dan kekeringan selama surut rendah yang berkepanjangan (Chao et al., 1993; Conand, 1996; 
Conand \& DeRidder, 1990; Harriott, 1982; Purwati, 2004; Uthicke, 1997). Untuk populasi Holothuria atra di perairan Medana yang secara umum lahan relatif luas, sirkulasi air cukup baik, dan belum ada polusi (Purwati et al., 2008), maka faktor yang mungkin mendorong terjadi reproduksi aseksual adalah kegagalan reproduksi seksual. Aspek ini perlu dibuktikan pada penelitian-penelitian yang akan datang. Kemungkinan lain faktor genetik, yaitu dugaan bahwa populasi fissiparous dari spesies tertentu yang mengekspresikan reproduksi aseksual memiliki variasi genetik yang berbeda dari populasi dan spesies yang sama tetapi tidak melakukan reproduksi aseksual. Tema ini akan menjadi topik menarik untuk penelitian yang akan datang.

Keuntungan dan kerugian reproduksi aseksual sebagai pilihan pemulihan populasi timun laut telah ditelaah oleh Purwati \& Dwiono (2008). Secara teknis, reproduksi aseksual memiliki peluang yang tinggi untuk diterapkan karena dapat dimulai dengan sedikit individu dengan tingkat kelangsungan hidup tinggi (Dwiono et al., 2008). Saat ini, berlangsung penelitian lanjutan untuk mengetahui kelangsungan hidup individu timun laut Holothuria atra hasil pembelahan (fission) buatan di lingkungan alami. Keberhasilan pemulihan populasi timun laut fissiparous melalui penebaran individu hasil pembelahan akan menjadi salah satu upaya mengurangi ancaman penurunan populasi yang berakibat dipertimbangkannya timun laut untuk dimasukkan sebagai obyek Convention International on Trade of Endangered Species.

\section{KESIMPULAN}

1. Populasi Holothuria atra di perairan Medana melakukan perkembangbiakan secara aseksual sepanjang tahun dengan laju dan intensitas yang bervariasi. Dengan mempertimbangkan laju pembelahan yang cukup besar, maka fenomena pembelahan ini dapat dianggap sebagai strategi yang berperan dalam mempertahankan populasi.

2. Untuk populasi yang diteliti, kehadiran reproduksi aseksual merupakan strategi timun laut Holothuria atra untuk mempertahankan kelangsungan hidup. Sementara itu, fenomena reproduksi aseksual membuka peluang pemanfaatan karekteristik biologis ini sebagai cara perbanyakan yang dapat diterapkan untuk memulihkan populasi timun laut fissiparous lain yang mengalami lebih tangkap.

\section{PERSANTUNAN}

Kegiatan dari hasil riset teripang Indonesia: Strategi mencapai populasi reproduktif alami, T. A. 2007, di
Unit Pelaksana Teknis Loka Pengembangan Bio Industri Laut, Pemenang-Lombok Barat. Ucapan terima kasih disampaikan pada para teknisi yang menjadi anggota Tim Penelitian, Abdul Basir Kaplale dan Nurhalis Tarmin, serta personil lain di Unit Pelaksana Teknis Loka Pengembangan Bio Industri Laut-Pusat Penelitian Oseanografi Lembaga IImu Pengetahuan Indonesia Mataram atas bantuan yang diberikan dalam pelaksanaan penelitian ini.

\section{DAFTAR PUSTAKA}

Aziz, A. \& Hakim, I. A. 2001. Fauna ekhinodermata perairan terumbu karang Bakauheni dan sekitarnya. Pesisir dan Pantai Indonesia VI. Pusat Penelitian dan Pengembangan Oseanologi. Lembaga IImu Pengetahuan Indonesia. Jakarta. pp. 65-129.

Chao, S. M., Chen, C. P., \& Alexander, P. S. 1993. Fission and its effect on population structure of Holothruia atra (Echinodermata: Holothuroidea) in Taiwan. Marine Biology. 116. 109-115.

1994. Reproduction and growth of Holothuria atra (Echinodermata: Holothuroidea) at two contrasting sites in southern Taiwan. Marine Biology. 119. 565-570.

Conand, C. 1996. Asexual reproduction by fission in Holothuria atra: Variability of some parameters in populations from the tropical Indo-Pacific. Oceanologia Acta. 19. 3-4. 209-216.

Conand, C., Armand, J., Dijoux, N., \& Garryer, J. 1998. Fission in a popuation of Stichopus chloronotus on Reunion Island, Indian Ocean. SPC Beche de mer Info. Bulletin. 10. 15-23.

Conand, C. \& DeRidder, C. 1990. Reproduction asexuee par scission chez Holothuria atra (Holothuroidea) dens des popuations de platiers recifaux. In DeRidder, C. Dubuis, Lohaye, \& Jangoux (eds.). Echinoderm Research. Balkema. Rotterdam. pp. 71-75.

Conand, C., Morel, C., \& Mussard, R. 1997. A new study of asexual reproduction in holothurians: fission in Holothuria leucospilota populations on Reunion Island in the Indian Ocean. SPC Bechede mer Info. Bulletin. 9. 5-11.

Crozier, W. J. 1917. Multiplication by fission in holothurians. The American Naturalist. 51. 560566 . 
Deichmann, E. 1922. On some cases of multiplication by fission and of coalescence in holothurians, with notes on the synonimy of Actinopyga parvula (Sel.). Papers from Dr. Th. Mortensen's Pacific Expedition 191401916. pp. 199-214.

Dwiono, S. A. P., Indriana L. F., Purwati, P., \& Fahmi, V. 2008. Perbanyakan Holothuria atra (Echinodermata: Holothuroidea) melalui stimulasi pembelahan. OLDI. (submitted). $16 \mathrm{p}$.

Emson, R. H. \& Wilkie, I. C. 1980. Fission and autotomy in Echinoderms. Oceanography Marine Biology Ann. Reserach. 18. 155-250.

Emson, R. H. \& Mladenov, P. V. 1987. Studies of the fissiparous holothuria Holothuria parvula (Selenka) (Echinodermata: Holothuroidea). Journal Exp. Marine Biology and Ecology. 3. 195-211.

Franklin, S. E. 1980. The reproductive biology and some aspects of teh population ecology of the holothurian Holothuria leucospilota (Brandt) and Stichopus chloronotus (Brandt). Sydney University. $250 \mathrm{p}$.

Harriott, V. 1980. The ecology of holothurian fauna of Heron reef and Moreton Bay. Master Thesis. University. Queensland. Australia. 153 p.

1982. Sexual and asexual reproduction of Holothuria atra, Jaeger at Heron Island Reef. Great Barrier Reef. Mem. Aust. Mus. 16. 53-66.

Hartati, S. T., Suprapto, Wahyuni I. S., \& Zainy R. 2002. Beberapa aspek biologi teripang di perairan Kepulauan Seribu. Jurnal Penelitian Perikanan Indonesia. 8. 113-124.

Kohtsuka, K., Arai S., \& Uchimura, M. 2005. Observation of asexual reproduction by natural fission of Stichopus horrens Selenka in Okawa Island, Japan. SPC Beche de mer Info. Bulletin, 22. 23-24.

Purwati, P. 2001a. Ekspresi fission dan konsekuensinya bagi populasi fisiparous Holothuroidea (Echinodermata). Oseana. XXVI. 4. 33-41. 2001b. Reproduction in Holothuria leucospilota Clark 1920 in tropical Darwin waters, NT Australia. Master Thesis. Northern Territory University. $147 \mathrm{p}$.

2004. Fissiparity in Holothuria leucospilota from tropical Darwin waters. Northern Teritorry Australia. SPC Beche de mer Info Bulletin. 26-33.

-_- 2006. Teripang, biodiversitas, dan permasalahanya di Indonesia. Laporan Akhir Program Riset Kompetitif. Sensus Biota Laut. Lembaga IImu Pengetahuan Indonesia. Jakarta. $71 \mathrm{p}$.

Purwati, P. \& Dwiono, S. A. P. 2005. Fission inducement in Indonesian holothurians. SPC Beche de mer Info. Bulletin. 22. 11-15.

Purwati, P., Dwiono S. A. P., Widianwary P., Setyawan W. B., Kusmanto E., \& Mauliputra B. 2008. Timun laut Lombok Barat. ISOII Jakarta. 71 p.

Purwati, P. \& Dwiono S. A. P. 2007. Fission inducement in Holothuria atra: Changing in morphology and body weight. Marine Research Indonesian. 32. 1. 1-6.

Smiley, S., McEun F. S., Chaffe C., \& Krishnan S. 1988. Echinodermata: Holothuroidea. In Giese, A. C. (ed.). Reproduction of Marine Invertebrates. Vol. 6. Academic Press. New York. pp. 663-749.

Townsley, S. J. \& Townsley M. P. 1973. A preliminary investigation of the biology and ecology of the holothurians at Fanning Island, Hawaii Inst. Geophysic. University Hawaii. Hawaii. pp. 173-186.

Uthicke, S. 1997. Seasonality of asexual reproduction in Holothuria (Halodeima) atra, Holothuria $(\mathrm{H})$ edulis and Stichopus chloronotus (Holothuroidea: Aspidochirotida) on the Great Barier Reef. Marine Biology. 129. 435-441.

Yusron, E. 2003. Beberapa catatan fauna echinodermata dari perairan Tapak Tuan, Aceh Selatan, Nanggroe Aceh Darussalam. Makara. 7. 97-103.

2006. Komposisi spesies echinodermata di perairan Tanjung Pai Padaido, Biak Numfor-Papua. Jurnal Perikanan. VIII. 2. 282-289. 